\title{
Nilai Pendidikan Karakter Dalam Cerita Rakyat Asal-usul Upacara Bekakak di Provinsi Daerah Istimewa Yogyakarta
}

\author{
Riswanda Himawan ${ }^{1 *}$ \\ Riefda Arya Kelana ${ }^{1}$ \\ Imam Maulana Satiaji ${ }^{1}$ \\ ${ }^{*} 123$ Program Studi Pendidikan Bahasa dan \\ Sastra Indonesia, Fakultas Keguruan dan \\ Ilmu Pendidikan, Universitas Ahmad \\ Dahlan, Yogyakarta, Daerah Istimewa \\ Yogyakarta, Indonesia \\ *email: \\ Riswanda1700003043@webmail.uad.ac.id
}

Received: 30 Desember 2020

Accepted: 31 Maret 2021

Published: 31 Maret 2021

doi: 10.22236/imajeri.v3i2.6202

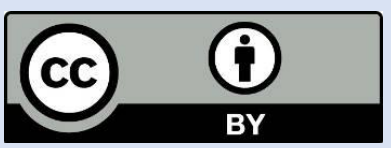

(C) 2021 Oleh authors. Lisensi Imajeri: Jurnal Pendidikan Bahasa dan Sastra Indonesia, Uhamka, Jakarta. Artikel ini bersifat open access yang didistribusikan di bawah syarat dan ketentuan Creative Commons Attribution (CCBY) license.

(http://creativecommons.org/licenses/by/4.0/).

\begin{abstract}
Abstrak
Cerita rakyat menyajikan banyak nilai yang dapat dipedomani, terutama nilai-nilai karakter. Oleh karena itu, tujuan dari penelitian ini untuk mendeskripsikan nilai pendidikan karakter yang terdapat dalam cerita rakyat Asal-Usul Kali Upacara Bekakak. Penelitian ini menggunakan metode deskriptif. Hasil penelitian menunjukkan bahwa nilai-nilai pendidikan karakter yang terdapat dalam cerita rakyat Asal-Usul Upacara Bekakak ini sangat penting diimplementasikan dalam kehidupan sehari-hari, nilai-nilai pendidikan karakter tersebut adalah; nilai karakter religius yang sangat erat hubunganya dengan Tuhan Yang Mah Esa, nilai karakter yang erat hubungannya dengan diri sendiri seperti tanggung jawab, setia, rajin dan nilai karakter yang erat hubungnnya dengan sesama seperti kasih sayang.
\end{abstract}

Kata kunci: Nilai Karakter; Dalam Cerita: Asal-Usul; Upacara Bekakak.

\section{Abstract}

The problem in this research is what is the value of character education contained in the folklore Origin of the Ceremony of the Bekakak Ceremony in the Special Province of Yogyakarta. This study aims to describe the value of character education contained in the folklore of the Origin of the Kali Bekakak Ceremony. This research uses descriptive method. The results showed that the values of character education contained in the folklore Origin of the Ceremony of the Bekakak Ceremony are very important to be implemented in daily life, the values of character education are; religious character values that are very closely related to God Almighty, character values that are closely related to oneself such as responsibility, faithful, diligent and character values that are closely related to others such as compassion.

Keywords: Character values; in folklore; Origins, Bekakak Ceremony.

\section{PENDAHULUAN}

Karya sastra dapat didefinisikan sebagai karya seni berbahasa di mana bahasa merupakan unsur kebudayaan yang ada dalam setia manusia, maka dari itu karya sastra sangat erat kaitannya dengan kebudayaan suatu masyarakat, karya sastra hadir sebagai dokumentasi kehidupan, karya sastra yang hadir tersebut memberikan nilai-nilai kehidupan yang dinamis, seiring dan sesuai dengan peradabaan tersebut (Supriyono, Wardani, \& Saddhono, 2018). 
Cerita rakyat merupakan bagian dari karya sastra yang hidup dan berkembang dalam suatu masyarakat yang dilestarikan dengan cara menularkannya melalui lisan ke lisan. Menurut Alpansori \& Wijaya (2014) Cerita rakyat juga merupakan bagian dari folklor yang pada era saat ini kehadirannya perlu dilestarikan, folklor sangat erat kaitannya dengan kehidupan masyarakat . Folklor menurut Danandjaja (dalam Syuhada et al., 2018) dapat didefinisikan sebagai bagian dari budaya suatu kolektif yang keberadaanya tersebar dan diwariskan di antara macam kolektif apa saja, dengan cara tradisional baik itu berbentuk lisan maupun bukan lisan.

Folklor memilik fungsi, (1) sebagai alat penghibur, (2) memberi pengetahuan, (3) sebagai sarana untuk memnunjang proses pendidikan, (4) sebagai ajang untuk bernostalgia (Amir, 2013). Salah satu folklor lisan yang sangat erat kaitannya dan sering digunakan oleh masyarakat sebagai sarana untuk hiburan adalah cerita rakyat (Puspitasari, Hidayatullah, \& Jupri, 2018). Cerita rakyat yang kehadirannya sangat dekat dengan masyarakat tersebut dapat diartikan sebagai bagian dari sastra daerah, yang merupakan ekspresi budaya suatu masyarakat disampaikan secara langsung dengan berbagai macam aspek budaya dan juga aspek susunan nilai sosial masyarakat tersebut. Maka dari itu cerita rakyat biasanya mengandung berbagai macam nilai, yang dapat digunakan oleh masyarakat sebagai pedoman dalam berkehidupan (Syuhada et al., 2018). Di antara nilai tersebut misalnya nilai religiositas (Hidayatullah, 2020) dan juga nilai karakter (Dewi, Hidayatullah, \& Puspitasari, 2020).

Nilai dapat diartikan sebagai suatu ukuran, patokan, yang dianut dan menjadi landasan masyarakat dalam berkehidupan, nilai biasanya terkait dengan berbagai hal yang mengandung kebenaran, pantas, dan luruh (Rosmana, 2010). Salah satu nilai yang terdapat dalam cerita rakyat adalah nilai pendidikan karakter, pendidikan karakter merupakan upaya yang dibentuk dan disusun serta dirncanakan secara sistematis untuk membantu peserta didik dalamm memahami nilai-nilai tindak yang erat hubungannya dengan Tuhan, dir sendiri, sesame manusia, lingkungan, serta nusa dan bangsa yang semuanya itu terbentuk dalam pikran, sikap, rasa, juga perkataan berlandaskan norma yang berlaku, hukum yang berlaku, budaya masyarakat, yang berlaku dalam lingkungan masyarakat tersebut (Inriani, 2017). Pendidikan karakter sangat diperlukan dan harus tertanam dalam diri manusia, karena pendidikan karakter mempunyai peranan yang sangat penting untuk mengatur serta membatasi perilaku manusia dalam berkehidupan. Rosidatun (2018) menyatakan bahwasanya karakter merupakan dorongan pilihan untuk menentukan hal yang terbaik dalam kehidupan manusia.

Nilai-nilai dalam pendidikan karakter dapat diklasifikasikan ke dalam beberapa kelompok (Yaumi dalam Idhawati, 2017). Pertama Nilai pendidikan karakter yang berkaitan hubungannya dengan Tuhan, niali-nilai, salah satu nilai yang termasuk dalam kelompok ini adalah nilai religius, religius dapat diartikan sebagai sifat-sifat religi yang melekat dalam diri seseorang, sifat religi dapat diwujudkan dalam perilaku, toleransi kepada seseorang yang berbeda agama dan sebagainyaNilai karakter yang kedua adalah karakter yang hubungannya dengan diri sendiri, perilaku yang termasuk ke dalam kelompok ini adalah sebagai berikut;(a) Jujur, jujur merupakan perilaku yang mendasari dirinya sebagai orang yang dapat dipercaya oleh orang lain. (b) Tanggung jawab, tanggung jawab merupakanperilaku untuk 
melaksanakan tugas yang sudah menjadi kebiasaannya, orang yang memiliki siakp tersebut pasti tertanam juga sifat berbuat kebaikan dan tidak akan menunjukkan kesalahan atau melempar kesalahan pada orang lain dalam setiap permasalahan yang dihadapi. (c) Disiplin, disiplin merupakan perilaku yang menunjukkan tertib seseorang terhadap ketentuan dan peraturan yang diberikan. (d) bekerja keras, bekerja keras menujukkan upaya sungguhsungguh baik itu dalam belajar, bekerja dan juga berusaha. Ketiga Nilai karakter yang hubungannya dengan sesama, ujud perilaku yang termasuk dalam kelompok ini adalah peduli sosial, peduli sosial merupakan sikap atau perilaku yang selalu ingin memberikan bantuan kepada orang lain. Ketiga, nilai karakter berikutnya adalah karakter yang hubungannya dengan lingkungan, salah satu ujud perilaku yang termasuk ke dalam kelompok ini adalah toleransi, toleransi merupakan sikap atau perbuatan yang menunjukkan sikap menghargai perbedaan agama, ras, dan suku yang berbeda dari dirinya. Kelima,yakni nilai pendidikan karakter yang hubungannya negara, seperti semangat nasionalisme, cinta tanah air dan sebagainya.

Iswahyuningtyas (2012) menyatakan bahwasanya terdapat sembilan pilar dalam pendidikan karakter, pilar-pilar tersebut adalah sebagai berikut; (a) cinta tuhan serta mencintai alam beserta isinya, (b) tanggung jawab, kedisiplinan, dan kemandirian, (c) kejujuran, (d) menghormati dan santun, (e) kasih sayang, setia dan kepedulian, (f) percaya diri, kreatif, pantang menyerah, (g) keadilan dan kepemimpinan, (h) baik dan rendah hati, (i) toleransi, cinta damai dan persatuan.

Berkaitan dengan penelitian mengenai nilai karakter yang ada dalam cerita rakyat, penelitian yang relevan dan lebih dahulu dilakukan oleh (Idhawati, 2017)dengan penelitian skripsi yang berjudul Nilai-Nilai Pendidikan Karakter Yang Terkandung Dalam Novel Anak Rantau Karya Ahmad Fuadi. Penelitian yang dilakukan oleh Idhawati (2017) memiliki kesamaan dengan penelitian yang akan peneliti lakukan, di mana kedua penelitian ini samasama meneliti mengenai nilai-nilai karakter dalam karya sastra, perbedaanya penelitian yang dilakukan oleh Idhawati (2017) meneliti mengenai Novel, sedangkan penelitian yang akan peneliti lakukan meneliti mengenai cerita rakyat. Kedua, penelitian yang dilakukan oleh Sugeng Supriyono, Nugraheni Eko Wardani, Kundharu Saddhono (2018) dengan penelitian artikel jurnal ilmiah Scholaria yang berjudul Nilai Pendidikan Karakter Sajak"Bulan Ruwah" karya Subagjo Sastrowardoyo Dalam Pembelajaran Sastra. Penelitian ini memiliki persamaan dan perbedaan dengan penelitian yang akan peneliti lakukan, persamaannya kedua penelitian ini sama-sama meneliti mengenai nilai pendidikan karakter, sedangkan perbedaanya bahwa penelitian yang dilakukan oleh Supriyono et al. (2018) meneliti mengenai sajak, dan penelitian yang akan dilakukan oleh peneliti meneliti mengenai cerita rakyat. Ketiga, penelitian yang relevan dan lebih dahulu dilakukan oleh Esma Junaini, Emi Agustina, Amril Canrhas (2017) dengan penelitian yang terdapat dalam artikel jurnal ilmiah Korpus dengan judul Analisis Nilai Pendidikan Karakter Dalam Cerita Rakyat Seluma. Penelitian ini memiliki persamaan dengan penelitian ini yakni sama-sama meneliti mengenai sastra lisan atau dalam hal ini adalah cerita rakyat. 
Berdasarkan uraian yang telah disampaikan, penelitian dengan judul "Nilai Pendidikan Karakter Dalam Cerita Rakyat Asal-Usul Upacara Bekakak Di Provinsi Daerah Istimewa Yogyakarta sangat penting dilakukan, selain digunakan sebagai sumber refrensi, pengetahuan, dan melestarikan sastra khususnya sastra lisan yang ada di Daerah Istimewa Yogyakarta pada era revolusi industri seperti yang terjadi saat ini, penelitian ini juga berfungsi untuk menganalisis nilai karakter yang terdapat dalam cerita rakyat "Asal-Usul Upacara Bekakak", sehingga akan memudahkan masyarakat pembaca untuk mengetahui dan mengimplemantasikan nilai pendidikan karakter yang ada dalam cerita rakyat tersebut. Upacara bekakak yang masih ada hingga saat ini menjadikan alasan tersendiri bagi peneliti untuk lebih mengetahui dan mengulas lebih dalam nilai karakter yang ada dalam upacara tersebut melalui cerita rakyat ini .

\section{METODE}

Metode yang digunakan dalam penelitian ini adalah metode deskriptif kualitatif, yakni prosedur yang mengandung dan menghasilkan data secara tertulis mengenai nilai pendidikan karakter yang terdapat dalam cerita rakyat "Asal-Usul Upaca Bekakak". Endraswara (2008) menyatakan bahwasannya penelitian kualitatif menghasilkan serta menggunakan data utama berupa kata-kata. Objek dari penelitian yang dilakukan dalam penelitian ini adalah cerita rakyat "Asal-Usul Upacara Bekakak" yang diadopsi secara daring. Teknik pengumpulan data yang digunakan dalam penelitian ini menggunakan teknik baca dan teknik catat, sedangkan analisis datanya menggunakan teknik teknik membaca cerita tersebut, kemudian menandai apa yang dikaji dalam hal ini adalah nilai pendidikan karakter dalam cerita, kemudian data tersebut dicatat. Data-data yang terkumpul nantinya akan diklarifikasi kembali, dengan menggunakan berbagai macam refrensi, refrensi tersebut adalah pendapat para ahli serta beberapa hasil penelitian yang relvan dan lebih dahulu dilakukan. Penelitian mengenai "Nilai Pendidikan Karakter Dalam Cerita Rakyat Asal-Usul Upacara Bekakak" tidak hanya berhenti pada proses analisis data saja, namun data yang terkumpul nantinya juga akan disimpulkan.

\section{HASIL DAN PEMBAHASAN}

Berdasarkan hasil analisis ditemukan 5 jenis pendidikan karakter dalam cerita rakyat "AsalUsul Upacara Bekakak" nilai-nilai pendidikan karekter tersebut dapat djelaskan sebagai berikut:

\section{Religius}

Nilai karakter dalam cerita rakyat ini, yang kaitannya sangat erat dengan Tuhan Yang Maha Esa, dapat dilihat dari kutipan teks cerita berikut ini; "Mengetahui keresahan itu, Sri Sultan Hamengkubuwono I, pun bertitah kepada masyarakat Ambarketawang agar setiap bulan Sapar, diperingati dengan mengadakan upacara slametan. Tujuannya untuk memohon ke[pada Tuhan yang Maha Esa masyarakat terlindung dari segala bentuk musibah"

Berdasarkan kutipan tersebut, dapat dilihat bahwasannya dalam cerita ini, upacara slametan diadakan sebagai bentuk permohonan atau doa yang dilakukan oleh masyarakat kepada sang pencipta agar mereka terhindar dari segala bentuk musibah. Nilai karakter yang erat hubungannya dengan tuhan yang maha esa jika dilihat dari kutipan tersebut adalah 
religius, sikap religius ditunjukkan dari perilaku tokoh yang diwajibkan untuk mengadakan upacara slametan agar mereka terhindar dari segala bentuk musibah.

Hal ini sangat sesuai dengan pendapat Yaumi (dalam Idhawati, 2017) yang menyatakan bahwa pendidikan karakter yang berkaitan hubungannya dengan Tuhan Yang Maha Esa, niali-nilai, salah satu nya adalah nilai religius, religius dapat diartikan sebagai sifat-sifat religi yang melekat dalam diri seseorang. Religius dalam cerita ini terlihat bahwasannya masyarakat sering atau bahkan diutus untuk melakukan upacar slametan sebagai wujud mereka berdoa terhadap Tuhan Yang Maha Esa agar mereka terhindar dari segala musibah.

\section{Setia}

Nilai pendidikan karakter berikutnya yang terdapat dalam cerita rakyat "Asal-Usul Upacara Bekakak" adalah kasih sayang dan setia, nilai pendidikan karakter tersebut dapat dilihat dari kutipan cerita berikut ini; " Dua abdi yang paling setia adalah sepasang suami istri bernama Kyai dan Nyai Wirasuta. Keduanya adalah abdi dalem penongsong, yakni abdi dalem yang kesehariannya bertugas memayungoi Sri Sultan Hamengkubuwono I. Kemana pun Sri Sultan Hamengkubuwono I pergi, mereka berdua selalu setia turut serta membawa paying kebesaran keraton"

Dari penggalan cerita di atas, dapat diketahui bahwasanya karakter setia yang dilakukan oleh kedua abdi kepada Sri Sultan Hamengkubuwono I, mereka berdua selalu setia membawakan paying untuk memayungi Sri Sultan sebagai tuannya. Setia dalam KBBI (2016) dapat diartikan sebagai berpegang teguh pada janji, mengerjakan selalu tugas meski di rasa

berat. Kedua tokoh tersebut sangat setia karenma mereka memegang teguh dan selalu mengerjakan tugas untuk memayungi sang Raja ke manapun beliau pergi, di mana tugas tersebut terlihat sangat berat menurut pandangan masyarakat lain. Masyarakat pembaca dapat mencontoh karakter setia ini untuk selalu patuh, dan mengerjakan apa yang menjadi tugasnya, selalu setia mamatuhi tugas nya untuk memberikan rasa senang, kepada pemimpinnya.

\section{Tanggung Jawab}

Nilai pendidikan karakter yang terdapat dalam cerita rakyat "Asal-Usul Upacara Bekakak" berikutnya adalah tanggung jawab, tanggung jawab dapat didefinisikan sebagai tanggung jawab merupakan sikap untuk melaksanakan tugas yang menjadi kewajibannya, tanggung jawab merupakan cerminan seseorang dalam berbuat kebaikan dan tidak akan menyalahkan orang lain dalam setiap permasalahan yang dihadapi. Yaumi (dalam Idhawati, 2017) Tanggung jawab dalam cerita ini dapat kita lihat melalui kutipan cerita berikut ini: "Suatu ketika datanglah utusan dari keraton hendak menemui Sri Sultan Hamengkubuwono I di tempat peristirahatannya, Ampun Kanjeng dalem gusti, Bagimana perkembangan keraton kita? "tanya Sultan", Pembangunan keraton telah usia, dan keraton siap untuk ditempati, bagus kalau begitu, besok pagi kami akan kembali ke keraton, "ujar Sultan”.

Berdasarkan cerita tersebut, nilai tanggung jawab yang diperlihatkan oleh utusan keraton terhadap Sultan terlihat ketika utusan ditanya mengenai perkembangan pembangunan keraton oleh Sultan, utusan tersebut menjawab pembanguna keraton sudah siap dan sudah selesai. Hal ini menunjukkan bahwasanya utusan yang diberi tuga untuk selalu mengawasi dalam hal pengerjaan pembanguna keraton sudah menjalankan tugas dengan baik, dibuktikannya dengan pembangunan keraton yang sudah selesai dan siap untuk ditempati. 
Nilai karakter tersebut dapat dicontoh oleh masyarakat pembaca agar selalu tanggung jawab terhadap tugas yang diberikan, tugas yang diberikan baik itu dari orang tua, atasan maupun sebagainya harus dilaksanakan dengan baik, agar karakter seseorang dapat terbangun melalui sikap atau perilaku tanggung jawab. Nilai karakter tanggung jawab termasuk ke dalam nilai karakter yang erat hubungannya dengan diri sendiri.

Rajin

Nilai karakter rajin dalam cerita rakyat ini dapat kita lihat dari kutipan cerita berikut ini "Selain setia, Kyai dan Nyai Wirasuta termasuk abdi dalem Sultan yang palin rajin. Di selasela menjalankan tugas kewajibannya, keduanya memlihara beragam hewan, seperti ayam, bebek, burung puyuh, merpati, kelinci, dan landak. Rajin dalam KBBI (2016) dapat diartikan sebagai suka bekerja, belajar dan sebagainya. Rajin di sini dapat kita lihat bahwasanya ke dua abdi dalem tersebut sangat rajin memelihara hewan peliharaan, di samping mereka bekerja sebagai abdi dalem Sri Suktan. Nilai karakter rajin ini sangat erat kaitannya dengan nilai karakter dengan diri sendiri. Masyarakat pembaca dapat mencontoh perilaku rajin ini dan diterapkan dalam kehidupan sehari-hari, misalnya rajin memelihara hewan sebagai simpanan tabungan, rajin menabung, bekerja, belajar dan sebagainya.

\section{Kasih Sayang}

Nilai karakter kasih sayang dalam cerita ini dapat dilihat dari penggalan cerita berikut ini pertama Di sela-sela menjalankan tugas kewajibannya, keduanya memlihara beragam hewan, seperti ayam, bebek, burung puyuh, merpati, kelinci, dan landak, mereka sangat menyayangi dan rajin merawat hewan-hewan peliharaan tersebut" kasih sayang yang pertama dalam cerita ini terlihat bbahwa ke dua abdi dalem tersebut sanga mencintai hewan-hewan peliharaanya, mereka rajin merawat, memberi makan hewan-hewan tersebut di sela-sela mereka bekerja sebagai abdi dalem kraton. Nilai karakter kasih sayang di sini dapat dikelompokkan sebagai nilai karakter yang erat hubungannya dengan sesama. Masyarakat pembaca dapat mencontoh nilai karakter ini dan diterapkan ke dalam kehidupan sehari-hari.

Kedua, nilai karakter kasih sayang yang kedua, dapat kita lihat dari penggalan ceritan berikut ini "Di istana Ngayogyakarta Hadiningrat Sri Sultan Hamengkubuwono I, duduk termenung mengenang abadi dalam nya itu. Hatinya sangat sedih karena kehilangan orangorang yang disayanginya, Kesedihan yang dialami sang raja, berbulan-bulan lamanya"

Dari kutipan tersebut, terlihat bahwasanya nilai karakter kasih sayang yang ditekankan dalam cerita ini terlihat ketika sang Raja termenung, memikirkan kepergian ke dua abdi dalem yang di sayanginya, abdi dalem yang telah pergi dalam hal ini meninggal tertimbun batu kapur akibat peristiwa runtuhnya Gunung Gamping yang menimpa pasenggrahan tempat ke dua abdi dalem itu tinggal, walaupun masyarakat masih percaya walau jasad mereka telah tiada, namun jiwa dan raga mereka masih ada di pesaangrahan tersebut. Rasa kasih sayang terlihat ketika sang Raja sulit melupakan jasa mereka, sang Raja belum percaya bahwa ke dua abdi dalem yang disayangi tersebut telah tiada, berdasarkan penjelasan di atas maka dapat diketahui bahwasannya sang Raja benar-benar menyayangi ke dua abdi dalem yang selalu rajin, patuh, tanggung jawab terhadap Raja. Sikap setia yang diwujudkan oleh abdi dalem tersebut membuat sang Raja sangat menyayangi mereka, hingga akhirnya sang Raja sulit merelakan kepergian kedua abdi dalem kesayangannya tersebut. 
Nilai karakter kasih sayang dalam kutipan cerita tersebut dapat dikelompokkan ke dalam nilai karakter yang sangat erat hubungannya dengan sesama, masyarakat pembaca dapat mencontoh perilaku Raja agar selalu menyayangi orang-orang terdekat mereka. Masyarakat dapat mengimpelmentasikan nilai karakter kasih sayang ini dalam kehidupan sehari-hari, baik itu di lingkungan keluarga, masyarakat, amupun bberbangsa dan bernegara.

\section{KESIMPULAN}

Berdasarkan hasil analisis mengenai "Nilai Pendidikan Karakter Dalm Cerita Rakyat Asal-Usul Upacara Bekakak" dapat disimpulkan bahwa nilai karakter yang ada dalam cerita rakyat ini adalah (1) nilai karakter yang erat hubungannya dengan Tuhan Yang Mah Esa, yakni religius, religius di sini dapat dilihat dari prilaku tokoh yang mematuhi perintah Raja untuk mengadakan upacara selametan sebagai wujud permohonan doa terhadap Tuhan Yang Maha Esa, agar terhindar dari segala bahaya. (2) nilai karakter yang erat hubungannya dengan diri sendiri, seperti rajin, tanggung jawab dan setia, hal ini ditunjukkan oleh perilaku tokoh dalam cerita yang menunjukkan beberapa nilai karakter tersebut. (3) nilai karakter yang erat hubungannya dengan sesama, seperti kasih sayang, hal ini ditunjukkan oleh perilaku sang Raja yang dalam aktu berbulan-bulan belum bisa menerima kenyataan bahasanya ke dua abdi dalem yang disayanginya itu pergi. Hasil analisis menunjukkan bahwasannya cerita ini lebih dominan memberikan nilai pendidikan karakter kasih sayang, dibuktikan dari beberapa kutipan cerita yang menunjukkan nilai karakter tersebut.

\section{DAFTAR PUSTAKA}

Alpansori, M. J., \& Wijaya, H. (2014). Nilai-Nilai Pendidikan Karakter Dalam Cerita Rakyat Sasak (Pendekatan Pragmatik). Educatio, 9(2), 308-326.

Amir, A. (2013). Sastra Lisan Indonesia. Yogyakarta: ANDI.

Danandjaja, J. (2002). Folklor Indonesia: Ilmu Gosip, Dongeng, dan lain-lain. Jakarta: Pustaka Utama Grafiti.

Dewi, T. U., Hidayatullah, S., \& Puspitasari, N. A. (2020). Analisis Nilai Karakter dalam

Naskah Wawacan Samun. Manuskripta, 10(2), 283.

Endraswara, S. (2011). Metode Penelitian Sastra. Yogyakarta: Medpress.

Hidayatullah, S. (2020). Religiositas Masyarakat Betawi Dalam Folklor. Aksara, 32(1), 7994. https://doi.org/10.29255/aksara.v32i1.478.79-94

Idhawati, D. (2017). Nilai-Nilai Pendidikan Karakter Yang Terkandung Dalam Novel Anak Rantau Karya Ahmad Fuadi. IAIN SALATIGA.

Inriani, K. (2017). Nilai Kearifan Lokal dalam Legenda Cerita Rakyat Muntok: Sebuah Kajian Pendidikan Karakter. In Seminar Bahasa dan Sastra (pp. 167-177).

Iswahyuningtyas, F. (2012). Nilai-nilai pendidikan karakter pada materi ajar bahasa indonesia kelas 2 sd terbitan tiga serangkai. Universitas Muhammadiyah Surakarta.

Junaini, E., Agustina, E., \& Canrhas, A. (2017). Analisis nilai pendidikan karakter dalam cerita rakyat seluma. Jurnal Ilmiah KORPUS, 1(1), 39-43.

Puspitasari, N. A., Hidayatullah, S., \& Jupri, A. R. (2018). Pembentukkan Karakter Anak dengan Menulis Dongeng. In Pesona: Pekan Seminar Nasional Pendidikan Bahasa dan Sastra Indonesia (Vol. 1, pp. 61-66).

Rosidatun. (2018). Model Impelmentasi Pendidikan Karakter. Gersik: Caramedia Comunicattion.

Rosmana, T. (2010). Mitos dan nilai dalam cerita rakyat masyarakat Lampung. Patanjala, 2(2), 191-206.

Supriyono, S., Wardani, N. E., \& Saddhono, K. (2018). Nilai Pendidikan Karakter Sajak 
"Bulan Ruwah" Karya Subagio Sastrowardoyo dalam Pembelajaran Sastra. Scholaria: Jurnal Pendidikan Dan Kebudayaan, 8(2), 120-131.

Syuhada, S., Murtadlo, A., \& Rokhmansyah, A. (2018). Nilai Dalam Cerita Rakyat Suku Dayak Tunjung Tulur Aji Jangkat Di Kutai Barat: Kajian Folklor. Ilmu Budaya: Jurnal Bahasa, Sastra, Seni Dan Budaya, 2(2), 188-195.

Yaumi, M. (2014). Pendidikan Karakter: Landasan, Pilar, dan Implementasi. Jakarta: Kencana Prenada Media Group. 